\title{
Comparative study of texture evolution in ARB processed AA2014, AA6063 and AA2014/6063 aluminium laminates
}

\author{
V. G. Arigela ${ }^{1,2}$, J. Scharnweber ${ }^{1}$, L. Lienshoeft ${ }^{1}$, P. Chekhonin ${ }^{1}$, R. Schaarschuch ${ }^{1}$, \\ S. K. Kolli ${ }^{2}$, N. R. Palukuri ${ }^{2}$, J. Rengaswamy ${ }^{2}$, W. Skrotzki ${ }^{1 *}$ \\ ${ }^{1}$ Institut für Strukturphysik, Technische Universität Dresden, 01062 Dresden, Germany \\ ${ }^{2}$ Department of Metallurgical and Materials Engineering, Indian Institute of Technology Roorkee, \\ Roorkee 247667, Uttarakhand, India
}

Received 9 February 2015, received in revised form 4 June 2015, accepted 4 June 2015

\begin{abstract}
Single phase aluminium laminates of AA6063, AA2014 and AA6063/AA2014 composites were produced by accumulative roll bonding processed up to 6 cycles. The microstructure and texture of the initial materials and the sheets after 6 cycles were studied using electron backscatter diffraction and X-ray diffraction, respectively. It is observed that 6 cycles lead to an ultrafine grained microstructure. In both the single phase laminates and the composite the texture consists of the typical components for rolling and shear deformation of face-centred cubic metals. For all texture components, the intensity in the composite is about the average of the intensities in the single phase laminates. Therefore, the deformation process in the individual layers of the composite is comparable with that in the single phase alloys.
\end{abstract}

K e y w o r d s: aluminium alloys, accumulative roll bonding, texture, microstructure

\section{Introduction}

Due to their relatively high specific strength, good formability and low price, aluminium alloys are extensively used in the aerospace and automobile industry. Further improvement by increasing their strength will extend their range of application. In accordance with the Hall-Petch relation [1], grain refinement can be used to strengthen metallic materials. Ultrafine grained microstructures can be achieved by many severe plastic deformation (SPD) techniques. The one that can be easily adopted by industry both in terms of design and economy is accumulative roll bonding (ARB) since it does not require any major modification of equipment design from the conventional setup [2]. Furthermore, ARB is one of the few SPD techniques that can be used to produce layered sheets and composites. Since its development [3], the ARB process was used to process a variety of metal sheets $[4-6]$. In order to optimize the material properties further, ARB lately is widely used to produce layered composites [7]. Due to their advantages men- tioned above, aluminium alloys receive particular attention [8-10]. Ideally, a composite sheet is composed and processed in a way, so that it combines the favourable properties of the single phase materials on the one hand and eliminates their shortcomings on the other. An example is the combination of a highstrength AA5754 and lower strength AA6014 which has the advantage of not showing flow lines during forming of the strong composite and thus having sufficient surface quality for vehicle outer skins [11]. Likewise, the aluminium alloy AA2014 used in this study has good strength but is prone to corrosion, while the AA6063 alloy is less strong but has excellent corrosion resistance [12]. Ideally, both the high strength and the good corrosion resistance of the single phase materials should be maintained in a lamellar composite produced by ARB. While a lot of publications on the texture development of ARB processed metals and composites [13-15] have been published, comparative studies addressing both the single phase and the equally processed composite are scarce. Nevertheless, such studies are important as they can help to un- 
derstand and maybe one day to predict how single phase properties combine in a composite. Therefore, in this paper the texture evolution of the aluminium alloys AA2014 and AA6063 processed by ARB is compared with that of the corresponding ARB composite. Besides, results on the microstructure evolution are presented.

\section{Experimental}

In this study, the aluminium alloys AA2014 (Cr-0.04, Cu-4.1, Fe-0.4, Mg-0.55, Mn-0.73, Si-0.7, Al balance (wt.\%), and AA6063 (Si-0.52, Mg-0.46, Mn0.132, Fe-0.15, Cu-0.015, Al balance (wt.\%), were used. The initial sheets were $1 \mathrm{~mm}$ thick, $30 \mathrm{~mm}$ in width and $200 \mathrm{~mm}$ in length. Prior to ARB, a solution heat treatment was conducted for $2 \mathrm{~h}$ at $520^{\circ} \mathrm{C}$ for AA6063 and for $2 \mathrm{~h}$ at $505^{\circ} \mathrm{C}$ followed by an over ageing for $17 \mathrm{~h}$ at $280^{\circ} \mathrm{C}$ for AA2014. Both heat treatments were finished by water quenching.

Before each ARB cycle, contact surfaces were wire brushed using a steel brush. ARB was performed at room temperature without lubrication. The diameter of the rolls amounted $110 \mathrm{~mm}$, the rolling speed was $2.75 \mathrm{~m} \mathrm{~min}^{-1}$ and the thickness reduction was $50 \%$. After each cycle, an intermediate annealing step (10 min at $280^{\circ} \mathrm{C}$ ) was conducted. ARB was performed up to 6 cycles resulting in sound and well bonded AA2014 and AA6063 laminate and AA6063/AA2014 composite sheets with a maximum of 64 layers and a total equivalent strain of 4.8. For all subsequent analyses the samples were cut by spark erosion.

Texture measurements were done on the transverse direction (TD) plane of the sheets using a HZG-4 $\mathrm{X}$-ray texture goniometer. To measure a sufficiently large area on the TD plane, 12 sheet pieces were stacked together and subsequently embedded. As the $\mathrm{X}$-ray spot covered an area of at least several $\mathrm{mm}^{2}$ the measured texture represented the global texture. The last preparation step was mechanical grinding with 4000 grid SiC paper. From 3 measured pole figures $((111),(200),(220))$ the orientation distribution function (ODF) was calculated using Labotex software (Labosoft) imposing orthorhombic sample symmetry. The volume fraction of ideal texture components was calculated using a $10^{\circ}$ spread around the ideal orientations.

The microstructure was investigated on the TD plane in a Zeiss ULTRA 55 scanning electron microscope using backscattered electrons (BSE) and the electron backscatter diffraction (EBSD) technique for imaging. Layer thicknesses in the composite after 6 ARB cycles as well as mean grain sizes of the initial states were measured using the line intercept method on BSE images, whereas all mean grain sizes after 6 ARB cycles were calculated from the EBSD map- pings using the line intercept method as well. EBSD acquisition and evaluation was conducted with the software Channel 5 (HKL technology) close to the quarter thickness of the sheets using $12 \mathrm{kV}$ acceleration voltage and a step size of $50 \mathrm{~nm}$. To avoid artefacts in the evaluated data, noise reduction of non-indexed areas was performed incompletely from 8 down to 5 neighbouring pixels. Specimen preparation for EBSD consisted of mechanical grinding down to 4000 grid $\mathrm{SiC}$ paper followed by electropolishing with Struers Lectropol- 5 at about $-5{ }^{\circ} \mathrm{C}$ and a voltage of $42 \mathrm{~V}$ using an electrolyte consisting of $91 \%$ ethanol and $9 \%$ perchloric acid.

\section{Results and discussion}

In the initial state, the recrystallized grains in both AA6063 and AA2014 are elongated along the rolling direction (RD) with mean grain sizes of $24 \mu \mathrm{m}$ in normal direction (ND) and $52 \mu \mathrm{m}$ in RD and of $20 \mu \mathrm{m}$ in $\mathrm{ND}$ and $40 \mu \mathrm{m}$ in RD, respectively (Figs. 1a,b). In AA2014, $\mathrm{CuAl}_{2}$ precipitates (white spots) are visible (Fig. 1b). After 6 ARB cycles, the AA6063/AA2014 composite consists of 64 alternating layers with a mean thickness of about $16 \mu \mathrm{m}$ for both AA6063 and AA2014, respectively, providing evidence of an uniform co-deformation of both phases despite AA2014 being significantly harder than AA6063 [12]. A certain amount of necking is observed (Fig. 1c), being more pronounced near the interfaces formed during the $4^{\text {th }}$ and $5^{\text {th }}$ cycle.

After 6 ARB cycles, the grain structure in both alloys (Figs. 2a,b) and the composite (Fig. 2c) is ultrafine and consists of a high percentage of high angle grain boundaries. In AA6063 and AA2014 the average grain size is $0.3 \mu \mathrm{m}$ in $\mathrm{ND}$ and $1.2 \mu \mathrm{m}$ in $\mathrm{RD}$ and $0.2 \mu \mathrm{m}$ in $\mathrm{ND}$ and $0.6 \mu \mathrm{m}$ in $\mathrm{RD}$, respectively. In the composite the microstructure of each phase is comparable with that of the corresponding alloy. The texture of the alloys in the initial state and after 6 ARB cycles for both the alloys and the composite are presented as $\varphi_{2}=\left(0^{\circ}\right.$, $\left.45^{\circ}, 65^{\circ}\right) \mathrm{ODF}$ sections in Figs. 3 and 4 , respectively. Figure 5 is a key-figure showing the position of selected ideal rolling, shear and recrystallization texture components within these sections. In the initial state the textures of both alloys are rather weak (Fig. 3) with maximum intensities being observed at the position of the ideal Cube component $(\{100\}<100>)$ with a rotation of $\pm 20^{\circ}-25^{\circ}$ about ND, which can be attributed to grain growth [16] during the annealing heat treatment. It should be mentioned that due to the position of the measured maxima, the Copper $(\mathrm{Cu},\{112\}<111>)$ component as a classical rolling component is neglected in favour of the Dillamore 

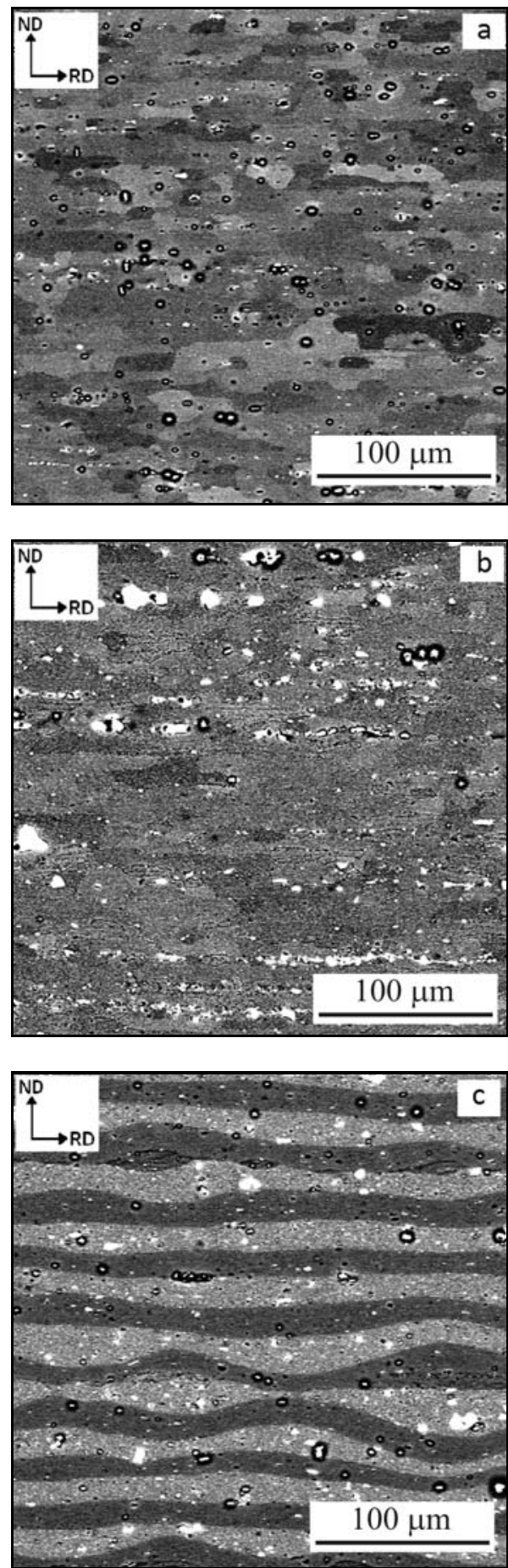

Fig. 1. BSE images of initial AA6063 (a), initial AA2014 (b) and of the composite (c) after 6 ARB cycles with AA2014 being the brighter phase.

(D, $\left\{\begin{array}{lll}4 & 4 & 11\end{array}\right\}<11118>$ ) component that stems from the shear between the layers and hence typically occurs in face-centred cubic (fcc) metals subjected to ARB [17].

During ARB the texture evolution of both alloys is dominated by the two major rolling components
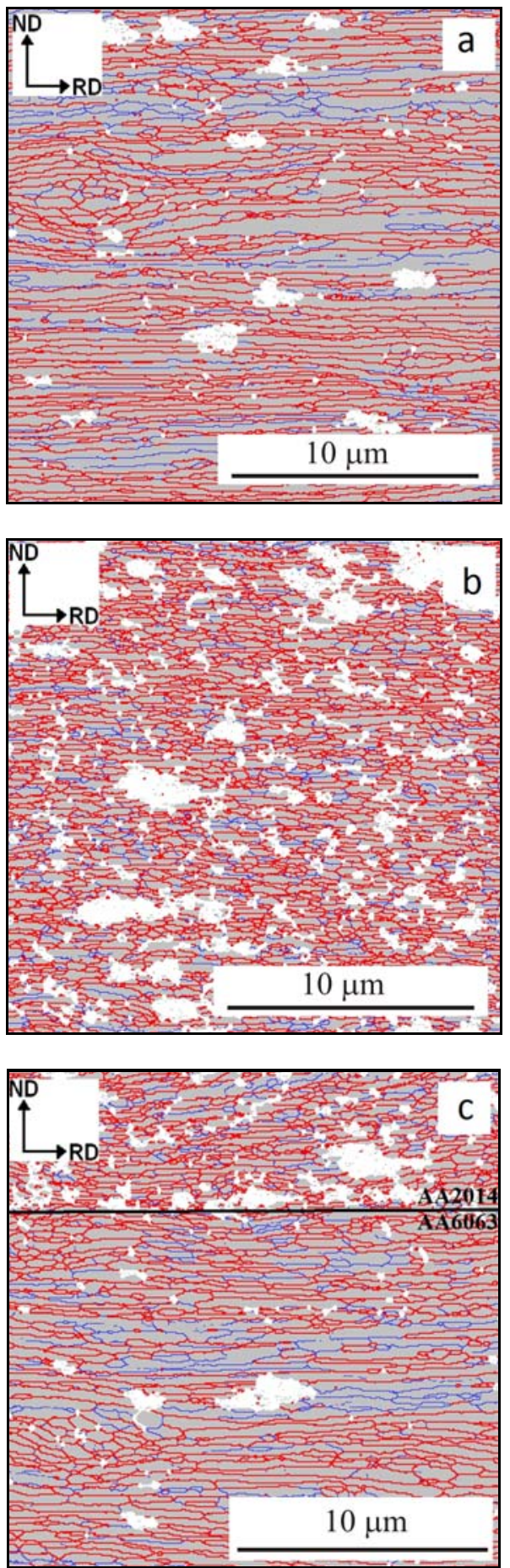

Fig. 2. EBSD grain boundary mappings of AA6063 (a), AA2014 (b) and the composite (c) after 6 ARB cycles. Low angle $\left(3^{\circ}-15^{\circ}\right)$ and high angle $\left(>15^{\circ}\right)$ grain boundaries are marked by blue and red lines, respectively. White areas are not indexed due to precipitates.

S $(\{123\}<634>)$ and D. Both components increase steadily with the cycle number. In comparison, the Brass (Bs) component is weaker, which is typical for fcc metals with a high stacking fault energy, and it sat- 


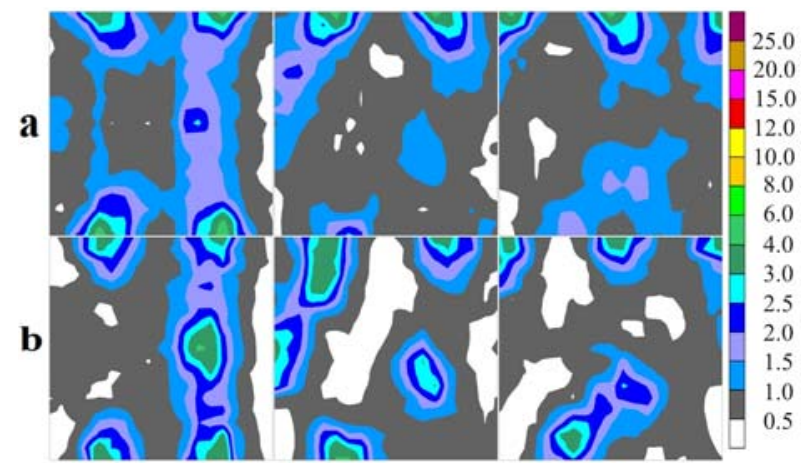

Fig. 3. ODF sections at $\varphi_{2}=0^{\circ}$ (left), $45^{\circ}$ (centre) and $65^{\circ}$ (right) for the initial state of AA6063 (a) and AA2014

(b).

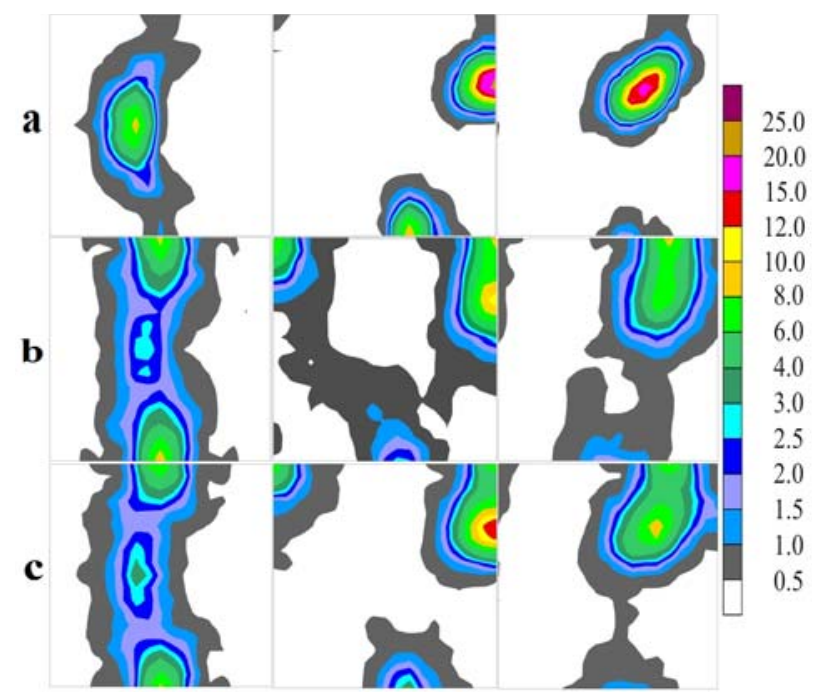

Fig. 4. ODF sections at $\varphi_{2}=0^{\circ}$ (left), $45^{\circ}$ (centre) and $65^{\circ}$ (right) after 6 ARB cycles for AA6063 (a), AA2014 (b) and the composite (c).

urates in both alloys after the first few ARB cycles. Also, in both alloys the Rotated Cube (C, $\{100\}$
$<110>$ ) component monotonously increases throughout the ARB processing, with the exception of the AA6063 alloy, where it abruptly disappears after the $6^{\text {th }}$ cycle. This shear component is caused by friction during the rolling process and is typical for ARB without lubrication. Cube and Goss $\{110\}<100>$ components are rather negligible in the alloys before and after ARB as well as in the composite. Other shear components (A $\{111\}<110>, \mathrm{A}_{1,2}\{111\}<112>$, B $\{112\}<110>$ ) did not develop. Both the increase of S, D and Bs is generally slower in AA2014 than in AA6063, where the volume fractions measured are significantly higher for the larger part of the ARB processing. This development may be explained by the high volume fraction of precipitates inside the AA2014 alloy. These precipitates change the deformation behaviour of the material in their surrounding and by that lead to a less pronounced texture development. However, friction in the harder AA2014 alloy is higher than in AA6063, which is responsible for the stronger C component in AA2014.

As can be derived from Fig. 6c the texture development in the composite is comparable to the arithmetical average of the two alloys. Combined with the microstructural evolution, this leads to the conclusion that the deformation process in the individual layers of the composite is similar to that in the single phase sheets. After 6 ARB cycles the spacing of the individual layers is much larger than the grain size in ND. Therefore, most of the grains remain unaffected by the interfaces. This may change after application of some additional ARB cycles, when the layer thickness approaches the dimension of the grain size along ND.

\section{Conclusions}

1. Sound composite sheets with sufficient bonding can be produced from AA6063 and AA2014 sheets using ARB. After 6 cycles, an ultrafine grained structure is reached.

2. The texture evolution in both alloys results in

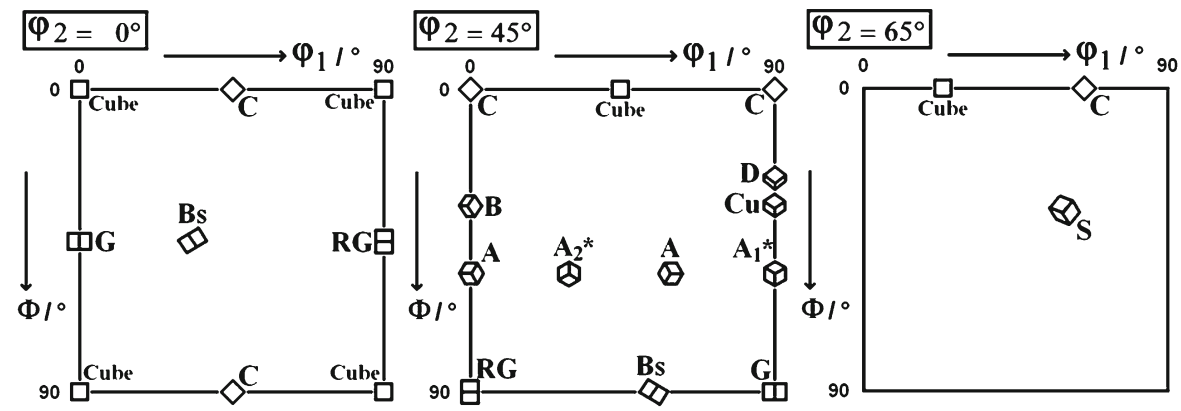

Fig. 5. ODF sections at $\varphi_{2}=0^{\circ}, 45^{\circ}$ and $65^{\circ}$ with ideal rolling and shear texture components within the rolling plane (RD vertical, TD horizontal for unit cell symbols; for details of texture components see text). 

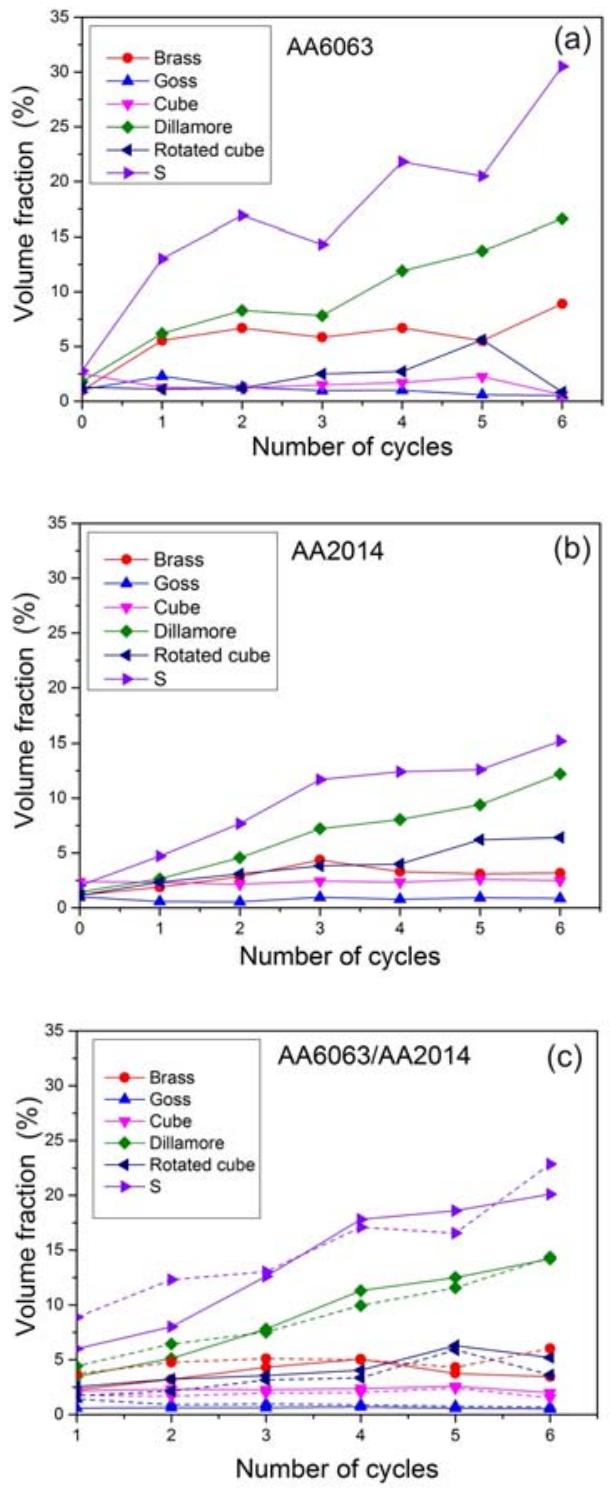

Fig. 6. Volume fraction of ideal components as a function of ARB cycles for AA6063 (a), AA2014 (b) and the composite (c). Dotted lines in (c) represent the arithmetical average of AA6063 and AA2014.

rolling and shear texture components typical for aluminium sheets processed by ARB.

3 . In the composite, the texture evolution as well as the microstructural development in each alloy does not seem to be affected by the other during ARB.

\section{Acknowledgements}

V.G.A. is grateful to DAAD for a research scholarship. This paper is dedicated to Prof. Pavel Lukáč on the occasion of his $80^{\text {th }}$ birthday.

\section{References}

[1] Hall, E. O.: Proc. Phys. Soc., 64, 1951, p. 747. doi:10.1088/0370-1301/64/9/303

[2] Estrin, Y., Vinogradov, A.: Acta Mater., 61, 2013, p. 782. doi:10.1016/i.actamat.2012.10.038

[3] Saito, Y., Tsuji, N., Utsunomiya, H., Sakai, T., Hong, R. G.: Scripta Mater., 39, 1998, p. 1221. doi:10.1016/S1359-6462(98)00302-9

[4] Saito, Y., Utsunomiya, H., Tsuji, N., Sakai, T.: Acta Mater., 47, 1999, p. 579. doi:10.1016/S1359-6454(98)00365-6

[5] Krallics, G., Lenard, J. G.: J. Mater. Process. Technol., 152, 2004, p. 154. doi:10.1016/j.jmatprotec.2004.03.015

[6] Karlik, M., Homola, P., Slamova, M.: J. Alloys Comp., 378, 2004, p. 322. doi:10.1016/j.jallcom.2003.10.082

[7] Chang, H., Zheng, M. Y., Gan, W. M., Wu, K., Maawad, E., Brokmeier, H. G.: Scripta Mater., 61, 2009, p. 717. doi:10.1016/j.scriptamat.2009.06.014

[8] Chekhonin, P., Beausir, B., Scharnweber, J., Oertel, C.-G., Jaschinski, J., Hausöl, T., Höppel, H. W., Brokmeier, H.-G., Skrotzki, W.: Mater. Sci. Forum, 702703, 2012, p. 151. doi:10.4028/www.scientific.net/MSF.702-703.151

[9] Roy, S., Nataraj, B. R., Suwas, S., Kumar, S., Chattopadhyay, K.: Mater. Design, 36, 2012, p. 529. doi:10.1016/j.matdes.2011.11.015

[10] Su, L., Lu, C., Tieu, A. K., Deng, G., Sun, X.: Mater. Sci. Eng A, 559, 2013, p. 345. doi:10.1016/j.msea.2012.08.109

[11] Kurtovic, A., Niendorf, T., Hausöl, T., Höppel, H. W., Göken, M., Maier, H. J.: Scripta Mater., 68, 2013, p. 809. doi:10.1016/j.scriptamat.2013.01.036

[12] Joseph, R. D.: Corrosion of Aluminum and Aluminum Alloys. Materials Park, ASM International 1999.

[13] Roy, S., Singh, D., Suwas, S., Kumar, S., Chattopadhyay, K.: Mater. Sci. Eng. A, 528, 2011, p. 8469. doi:10.1016/j.msea.2011.07.042

[14] Roy, S., Nataraj, B. R., Suwas, S., Kumar, S., Chattopadhyay, K.: J. Mater. Sci., 47, 2012, p. 6402. doi:10.1007/s10853-012-6567-z

[15] Chekhonin, P., Beausir, B., Scharnweber, J., Oertel, C.-G., Hausöl, T., Höppel, H. W., Brokmeier, H.G., Skrotzki, W.: Acta Mater., 60, 2012, p. 4661. doi:10.1016/j.actamat.2012.04.004

[16] Humphreys, F. J., Hatherly, M.: Recrystallization and Related Annealing Phenomena. 2nd Edition. Amsterdam, Elsevier 2004. ISBN: 978-0-08-044164-1

[17] Duckham, A., Knutsen, R. D., Engler, O.: Acta Mater., 49, 2001, p. 2739. doi:10.1016/S1359-6454(01)00166-5 